OPEN ACCESS

Edited by:

David Andrew Luther,

George Mason University,

United States

Reviewed by:

Tomasz S. Osiejuk,

Adam Mickiewicz University, Poland

Pierre J. Deviche,

Arizona State University, United States

${ }^{*}$ Correspondence:

Eira Bermúdez-Cuamatzin

eira.bc@gmail.com

Specialty section:

This article was submitted to

Behavioral and Evolutionary Ecology,

a section of the journal

Frontiers in Ecology and Evolution

Received: 08 April 2020

Accepted: 06 July 2020

Published: 24 July 2020

Citation:

Bermúdez-Cuamatzin E,

Delamore Z, Verbeek L, Kremer C and

Slabbekoorn H (2020) Variation in Diurnal Patterns of Singing Activity Between Urban and Rural Great Tits.

Front. Ecol. Evol. 8:246.

doi: 10.3389/fevo.2020.00246

\section{Variation in Diurnal Patterns of Singing Activity Between Urban and Rural Great Tits}

\author{
Eira Bermúdez-Cuamatzin*, Zoë Delamore, Laura Verbeek, Christoph Kremer and \\ Hans Slabbekoorn
}

Institute of Biology, Leiden University, Leiden, Netherlands

Human settlements and activities alter the natural environment acoustically and visually. Traffic noise and street lights are two of the most prominent pollutants which may affect animal activity patterns. Birds in urban areas have been reported to sing nocturnally and to have an earlier dawn chorus compared to their rural counterparts. However, few studies have measured whether singing more at night or earlier in the morning means singing less during daytime. It is therefore unclear whether they shift or extend or overall increase their activities. Furthermore, few studies on anthropogenic noise-related shifts in song activity replicated well at the habitat level. We recorded singing activity in urban and rural great tits (Parus major) for $24 \mathrm{~h}$ and sampled 11 urban-rural pairs of territories, inside and outside 11 different cities across the Netherlands. We found that urban birds sing earlier during the day, have similar singing effort in the dawn chorus, but sing less than rural birds during the rest of the day. The shift in timing between urban and rural birds was 22 min on average and resulted in more songs for urban birds during a less noisy time of the day. The lower singing activity over the day made that urban birds sang less when it was more noisy compared to the natural rhythm of rural great tits. We currently lack insight into whether these differences yield any positive or negative fitness consequences, but it is a clear case of how anthropogenic effects on the natural environment influence fundamental aspects of daily life in the animal communities with which we share the urban habitat.

\section{Keywords: birdsong, dawn chorus, diurnal patterns, traffic noise, temporal shift}

\section{INTRODUCTION}

Activity patterns are species-specific, typically driven by natural environmental and social cues (Aide et al., 2013; Frey et al., 2017), but can be affected by human disturbance (Barrueto et al., 2014; Lendrum et al., 2017; Gaynor et al., 2018). Some species are diurnal, others nocturnal, and many have crepuscular peaks of activity around dawn or dusk. These labels are typically based on activity biases in foraging, nest building, or moving around, but may also apply to preference period for vocal activity. Many mammals are naturally most active at night (Frey et al., 2017; Ogurtsov et al., 2018), but there are also reports on species that are diurnal in undisturbed areas and nocturnal where human are active or noisy during daytime (e.g., Martin et al., 2010; Marchand et al., 2014). Many species of birds peak in singing activity around dawn and in the morning (Bruni et al., 2014; Pérez-Granados et al., 2018), but also here urban species have been reported to be active at night and 
wake up earlier due to daytime noise pollution (Fuller et al., 2007; Dominoni et al., 2013; Swaddle et al., 2015). However, the nature of this shift is still not well understood as few studies on avian vocal activity patterns replicated well at the level of the habitat and few studies collected detailed data across the $24 \mathrm{~h}$ of a full day.

Most birds are more active during the day than during the night and often have a distinct peak in singing activity around dawn (Aide et al., 2013; Bruni et al., 2014; Pérez-Granados et al., 2018). Explanations for this activity bias to this early hour include coinciding peaks in female fertility and competitor risk, optimal air conditions for sound transmission, and low foraging profitability related to inadequate light conditions (Kacelnik and Krebs, 1983; Mace, 1987; Brown and Handford, 2003). Variation among species must be related to variation in species-specific physiology or sensory capacity, which would render a different trade-off among activities such as foraging and singing. Variation in timing does not only occur among species, but also within species. Seasonal variation, in particular in temperate zones, is driven by hormonal cycles related to the breeding season (Nottebohm, 1981; Ball, 1999), but also weather and habitat may affect singing effort and timing.

Natural variation in ambient noise and light conditions are known to affect singing activity and to explain variation in activity patterns among days. Cicada calling can be loud, in particular in tropical areas, and may drive bird species that overlap in song frequency use to adjust their timing (Hart et al., 2015). This is also the explanation for why high-frequency singing bird species rise later than low-frequency singers in tropical forests with intense nighttime cicada chorusing at high frequencies (Stanley et al., 2016). Birds in the temperate zone of rural North America were reported to sing earlier with full or third-quarter moon, which makes light levels to be higher at dawn (Bruni et al., 2014). An opposite effect has been found in temperate zones of both North-America and Europe for birds that delayed their dawn chorus and stopped singing earlier at dusk with cloud cover and rain, which obviously dims the light levels (Nordt and Klenke, 2013; Bruni et al., 2014; Da Silva et al., 2014). Understorey and canopy birds of tropical forests may even also exhibit lightlevel-related differences in vocal activity patterns (Blake, 1992; Berg et al., 2006).

The presence of human settlements and infrastructure can also alter environmental cues and make urban and rural birds of the same species wake up at different times (Bergen and Abs, 1997; Swaddle et al., 2015). Typically, urban birds are active earlier in the day and in the season compared to rural counterparts (Miller, 2006; Da Silva et al., 2015). Sometimes, differences in the morning are followed by differences in the rest of the day: short or disturbed nights may be compensated with a nap (Raap et al., 2016) or with just lower activity levels during daytime (de Jong et al., 2016). This may yield further divergence in daily activity patterns between birds of different habitats. Cartwright et al. (2014), for example, conducted a study with long-term passive recordings at three high-traffic and two lowtraffic sites in southern Ontario, Canada. They found that redwinged blackbirds (Agelaius phoeniceus) sang more at dawn and dusk at the rural sites and more during midday at the urban sites. Traffic noise and street lightening are two of the most prominent pollutants that are put forward as causing such divergence in avian rhythms (Nordt and Klenke, 2013; Lee et al., 2017), with sometimes sound put forward as most prominent factor (e.g., Fuller et al., 2007) and sometimes light (e.g., Da Silva et al., 2014).

Great tits are a great model system to study vocal variation and habitat-dependent song activity patterns. Males are highly vocal during the breeding season (Garson and Hunter, 1979), and they use distinct song types that are typically well contrasting with other songbird songs and known to play a role in territory defense and mate attraction (Krebs et al., 1978; Mace, 1987; Slagsvold et al., 1994). They occur in both urban and rural areas and typically sing close to their nest, which is often a nest box (e.g., Halfwerk et al., 2011, 2012). Such artificial nesting opportunities are usually easy to localize and are numerous in urban areas, but people also tend to provide them in many rural areas (e.g., at relatively isolated houses and farms, in recreational woodlands, on campings and holiday home parks, and in special study populations dedicated to scientific research). Great tits were also the model species in some of the early papers on habitatdependent song variation (Hunter and Krebs, 1979; Bergman, 1982; Lehtonen, 1983) and have been studied intensively for urban-rural comparisons (e.g., Slabbekoorn and den BoerVisser, 2006; Slabbekoorn and Ripmeester, 2008; Mockford and Marshall, 2009; Senar et al., 2017; Caorsi et al., 2019; Ulgezen et al., 2019). However, we still lack a well-replicated urban-rural comparison in great tits on the timing and amount of singing during the dawn chorus and the rest of the entire day.

In the current study, we recorded 24-h song activity cycles of a replicated set of individual great tits, in a paired sampling design. We recorded 11 pairs of territorial male birds, with each pair sampled during the same 24-h period, and consisting of an urban territory, with city noise and light conditions, and a more quiet and dark territory in a nearby rural woodland area. Pairs of birds were sampled in different cities across an area of 150 by $150 \mathrm{~km}$, from The Hague to Nijmegen and Amsterdam to the Belgian border. We aimed to answer the following questions: (1) Do urban great tits indeed sing earlier than nearby rural great tits? (2) Do urban great tits sing more or less, and shorter or longer, during the dawn chorus and more or less over the rest of the day after the dawn chorus? and (3) If there are differences in timing or amount of singing, can they be related to noise avoidance: Do great tits avoid singing during the most noisy times of the day? We expected that urban great tits would sing earlier than rural great tits. They may also stop earlier with the dawn chorus and sing less, which they may compensate by singing more the rest of the day. Alternatively, they may also show an effect of elevated competition for acoustic space by traffic noise during the rest of the day and sing less than their rural counterparts.

\section{MATERIALS AND METHODS}

\section{Study Sites and Passive Recording Approach}

This study was conducted from March to May of 2017 in 11 pairs of sampling sites, inside (urban) and outside (rural) 11 


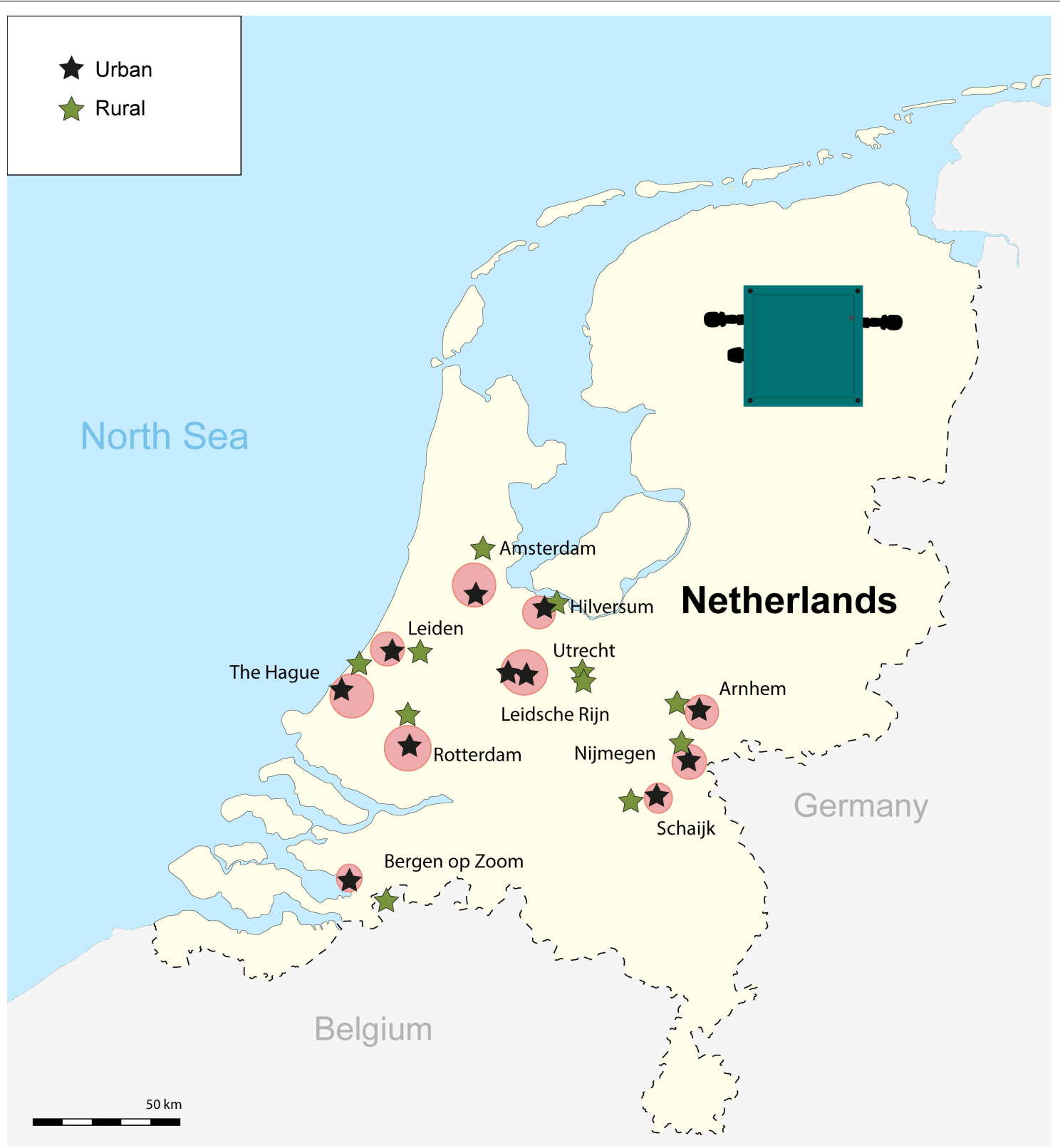

FIGURE 1 | Map with the locations of the 11 urban and rural pairs inside and outside main cities across the Netherlands. The black symbols represent the urban sites and the green symbols represent the rural sites. The red circles indicate the cities, with size reflecting relative size. We also show the image of the automatic recorders (Song Meter SM1) used to conduct our 24-h recordings.

cities across the Netherlands (Figure 1). In each of nine urbanrural pairs of sites, including the large cities (Dutch standards) of Amsterdam, Rotterdam, and The Hague, we sampled a great tit territory, well inside built-up areas at a relatively noisy place. A great tit territory away from houses and streets in woodland area, selected for being relatively quiet, was sampled in a random direction, $\sim 15-30 \mathrm{~km}$ apart from the urban site. Two urban-rural sites, Utrecht and Leidsche Rijn, were adjacent to each other, concerning historical old town and new residential areas, respectively, for which we sampled a matching rural site in woodland area east from Utrecht (see Figure 1).
Recordings within a pair of urban and rural sites were conducted synchronously on the very same day, while sampling of pairs were scattered through the season (Table $\mathbf{1}$ ).

In each of the 22 sampling sites, we selected a great tit male prominently advertising territory ownership by singing near a nest box. After the selection of the focal male, we observed the song posts defining his territory and we identified the boundaries of that territory. We recorded song activity for one cycle of $24 \mathrm{~h}$ for each great tit male with an automatic recorder (Song Meter SM1, Wildlife Acoustics Inc., Concorde, MA, United States, sample rate $44.1 \mathrm{kHz}, 16$-bits, stereo; see Figure 1). We placed 
TABLE 1 | Urban and rural pairs of sites and information about the date of recording, sunrise time (from https://cdn.knmi.nl), dawn chorus start, end and duration time, sunset time, last song of the daytime and total singing time.

\begin{tabular}{|c|c|c|c|c|c|c|c|c|c|}
\hline \multirow[t]{2}{*}{ Site } & \multirow[t]{2}{*}{ Urban/Rural } & \multirow[t]{2}{*}{ Date } & \multirow[t]{2}{*}{ Sunrise Time } & \multicolumn{3}{|c|}{ Dawn chorus } & \multirow[t]{2}{*}{ Sunset Time } & \multirow[t]{2}{*}{ Last song of the day } & \multirow[t]{2}{*}{ Total Singing } \\
\hline & & & & Start & End & Duration & & & \\
\hline Arnhem & Urban & 01-Apr & $7: 11$ & $5: 33$ & $7: 00$ & $1: 26$ & $20: 26$ & & \\
\hline Arnhem & Rural & 01-Apr & $7: 11$ & $6: 23$ & $7: 07$ & $0: 44$ & $20: 26$ & & \\
\hline Bergen op Zoom & Urban & 04-Apr & $7: 11$ & $5: 46$ & $6: 10$ & $0: 24$ & $20: 21$ & $20: 13$ & $14: 27$ \\
\hline Bergen op Zoom & Rural & 04-Apr & $7: 11$ & $6: 28$ & $8: 27$ & $1: 59$ & $20: 21$ & $20: 17$ & $13: 48$ \\
\hline Rotterdam & Urban & 08-Apr & $7: 01$ & $5: 32$ & $8: 05$ & $2: 32$ & $20: 28$ & 20:09 & $14: 36$ \\
\hline Rotterdam & Rural & 08-Apr & 7:01 & $5: 43$ & $6: 52$ & 1:08 & $20: 28$ & $20: 25$ & $14: 42$ \\
\hline Amsterdam & Urban & 11-Apr & $6: 52$ & $5: 57$ & $7: 01$ & $1: 04$ & $20: 32$ & $19: 52$ & $13: 55$ \\
\hline Amsterdam & Rural & 11-Apr & $6: 52$ & $6: 14$ & 7:04 & $0: 50$ & $20: 32$ & $19: 57$ & $13: 43$ \\
\hline Utrecht & Urban & 19-Apr & $6: 34$ & $5: 30$ & $6: 24$ & $0: 54$ & $20: 44$ & $17: 18$ & $11: 48$ \\
\hline Utrecht & Rural & 19-Apr & $6: 34$ & $5: 53$ & $7: 03$ & $1: 09$ & $20: 44$ & 20:06 & $14: 13$ \\
\hline Leidsche Rijn & Urban & 20-Apr & $6: 32$ & $5: 22$ & $5: 34$ & $0: 11$ & $20: 46$ & 13:05 & $7: 42$ \\
\hline Leidsche Rijn & Rural & 20-Apr & $6: 32$ & $5: 46$ & $6: 52$ & $1: 05$ & $20: 46$ & $19: 59$ & $14: 12$ \\
\hline Schaijjk & Urban & 24-Apr & $6: 22$ & $5: 43$ & $6: 43$ & $1: 00$ & $20: 50$ & 20:02 & $14: 19$ \\
\hline Schaijk & Rural & 24-Apr & $6: 22$ & $5: 44$ & $6: 21$ & $0: 36$ & $20: 50$ & $20: 19$ & $14: 34$ \\
\hline Hilversum & Urban & 27-Apr & $6: 17$ & $5: 37$ & $6: 14$ & $0: 36$ & $20: 24$ & $19: 58$ & $14: 20$ \\
\hline Hilversum & Rural & 27-Apr & $6: 17$ & $5: 38$ & $6: 42$ & $1: 03$ & $20: 24$ & $20: 25$ & $14: 47$ \\
\hline The Hague & Urban & 30-Apr & $6: 15$ & $4: 50$ & $6: 10$ & $1: 19$ & $21: 06$ & $20: 44$ & $15: 53$ \\
\hline The Hague & Rural & 30-Apr & $6: 15$ & $5: 34$ & $6: 32$ & $0: 57$ & $21: 06$ & $19: 58$ & $14: 24$ \\
\hline Nijmegen & Urban & 03-May & $6: 04$ & $5: 05$ & $6: 22$ & $1: 17$ & $21: 04$ & $20: 52$ & $15: 46$ \\
\hline Nijmegen & Rural & 03-May & $6: 04$ & $5: 45$ & $6: 13$ & $0: 28$ & $21: 04$ & $20: 23$ & $14: 38$ \\
\hline Leiden & Urban & 16-May & $5: 46$ & $4: 53$ & $5: 55$ & 1:01 & $21: 32$ & $20: 51$ & $15: 57$ \\
\hline Leiden & Rural & 16-May & $5: 46$ & $4: 59$ & $5: 56$ & $0: 56$ & $21: 32$ & $19: 34$ & $14: 34$ \\
\hline
\end{tabular}

Time is displayed in hours and minutes.

the recorder on a song post close to the nest box of the male great tit, which guaranteed high-quality recordings, as male tits sing close and often toward the nest box, prior to and during breeding activity (see Halfwerk et al., 2011, 2012). The automatic recorders were programmed to record a sequence of 241 -h recordings. Ending one recording and starting a following one, lasted $30 \mathrm{~s}$. We, therefore, miss data for a very short period every hour $(0.8 \%)$, and we had to take a shift into account of accumulating $30 \mathrm{~s}$ periods over the day, when attributing song activity to a particular hour slot. The Song Meters were placed during daytime, but all recordings started at 3:30 in the night. In one of the 22 sites, the city of Arnhem, our recording had stopped at 11:30 in the morning (well after the dawn chorus) for unknown reasons, and for some of the analyses, we therefore had to drop this pair of sites.

\section{Timing and Amount of Singing}

We used spectrograms generated in Avisoft-SASLab Lite 5.2.10 (sample rate $44.1 \mathrm{kHz}$, sample size 16-bits, FFT length $=256$ points, frame size $100 \%$, overlap $75 \%$, frequency resolution $172 \mathrm{~Hz}$, temporal resolution $1.45 \mathrm{~ms}$, Hamming window) to determine the timing and amount of singing of great tits during the 24-h cycles. We defined the start, duration and end of the dawn chorus for each male, as well as the last song of the day and the total singing time (Table 1). The start of the dawn chorus was simply the first song detected in our recordings. The end of the dawn chorus was determined by measuring song intervals: it was considered the end of the dawn chorus when a bird had not sung for longer than $7 \mathrm{~min}$. In a study by Naguib et al. (2019), 98\% of the inter-song intervals during the dawn chorus singing, before sunrise, were shorter than $7 \mathrm{~min}$, which was the reason to take this interval length as the end of dawn chorus criterion (c.f. Naguib et al., 2019). We expressed start and end times also relative to sunrise or sunset to allow comparisons across the season (Table 1). Furthermore, we counted the number of songs of the focal male every hour. Great tit males have small repertoires, around 2-6 types in our sample, and repeat the same song type for several minutes before they switch to a different song type (Halfwerk et al., 2012). The discrete nature of great tit song types further helped to extract target songs from the background with other songs from other species, and potentially furtheraway neighbors. Although focal males also moved around among different singing perches, and song amplitude on the recording varied accordingly, we rarely had any difficulty in distinguishing focal male song and faint songs of distant neighbors.

\section{Noise Measurements and Fluctuation Patterns}

We assessed the short-term amplitude levels of the background noise at each site, using a Voltcraft SL-100 sound level meter (range, 30-130 dB; A-weighting, fast response). All sites were measured once, associated with installing or collecting the Song Meter and thus associated with the paired assessment of singing 
activity throughout the season. All measurements were taken between 6:00 and 13:00 h, except for one pair of sites, which was measured late in the afternoon (see Table 2). We measured noise levels for $5 \mathrm{~min}$ : $1 \mathrm{~min}$ in each of the five directions (north, east, south, west, and up). During $1 \mathrm{~min}$, we recorded the highest amount of noise every $10 \mathrm{~s}$ ( 6 measurements per minute). Noise levels were averaged for each site. In addition, we analyzed the long-term noise fluctuations in each territory using our passive recordings from the Song Meters.

We analyzed relative noise fluctuations in time, using the longterm recordings, in two frequency bands: a low band between 200 and $400 \mathrm{~Hz}$ and a high band between 2000 and $4000 \mathrm{~Hz}$. The lower band reflects traffic activity well, as there are very few birds making sound below $400 \mathrm{~Hz}$ and traffic noise is biased toward low frequencies (Slabbekoorn and Peet, 2003). The high band reflects bird song activity, including the frequency range of the songs of great tits and excluding a major contribution from traffic noise. For each frequency band, we selected the highest amplitude in periods of $1 \mathrm{~min}$ using a power spectrum (FFT length: 256 points, window type: Hamming) generated in AvisoftSASLab Lite 5.2.10. To assess fluctuations in time, we took three of such 1 min amplitude measurements per hour. These three measurements were taken in three different time blocks within the hour: (1) from 0 to $20 \mathrm{~min}$, (2) from 20 to $40 \mathrm{~min}$, and (3) 40-60 min. We avoided songs from our focal great tit male in the one-min selections, and, when his dawn chorus singing was very dense, we occasionally merged separate periods from the same time block into a one-min composite selection. We averaged the three samples to get a single amplitude measure per hour. We determined relative noise level for each hour per territory by subtracting the hourly averages from the overall average of the day.

We assessed spectral differences in the ambient noise between urban and rural sites to provide the context of potential masking by spectral overlap that could drive the temporal patterns explored in our analyses. We used 20 one-min samples from our urban and rural sites, excluding songs from the focal bird, but taken from the morning hour with most singing activity

TABLE 2 | Times and dates for when short-term noise measurements were taken for each of the pairs of rural and urban sites.

\begin{tabular}{lcccc}
\hline & \multicolumn{3}{c}{ Times and dates short-term noise measurements } \\
\cline { 2 - 5 } Site & Rural & Date & Urban & Date \\
\hline Arnhem & $17: 02$ & 02-Apr & 10:19 & 02-Apr \\
Bergen op zoom & $06: 24$ & 05-Apr & 08:09 & 05-Apr \\
Rotterdam & $06: 50$ & 13-Apr & 08:24 & 09-Apr \\
Amsterdam & $08: 40$ & 12-Apr & 06:50 & 12-Apr \\
Utrecht & $06: 23$ & 20-Apr & $10: 09$ & 20-Apr \\
Leidsche Rijn & $07: 10$ & 21-Apr & $10: 35$ & 21-Apr \\
Schaijk & $08: 45$ & 25-Apr & 06:08 & 25-Apr \\
Hilversum & $10: 56$ & 28-Apr & 07:48 & 28-Apr \\
The Hague & $10: 20$ & 01-May & $10: 48$ & 29-Apr \\
Nijmegen & $11: 17$ & 04-May & $14: 59$ & 04-May \\
Leiden & $11: 39$ & 15-May & 12:35 & 17-May
\end{tabular}

(5.30-6.30) (Figure 2). Urban sites have relatively high amplitude levels in the low frequencies $(<3000 \mathrm{~Hz})$ in comparison to rural sites, and relatively low amplitude levels for high frequencies $(>3000 \mathrm{~Hz}$ ). These patterns reflect the prominent presence of traffic noise in urban sites (low frequencies) and more prominent presence of singing birds (high frequencies) in rural sites, which is in line with many other reports (e.g., Slabbekoorn and Peet, 2003; Pohl et al., 2009; Nemeth and Brumm, 2010).

\section{Statistical Analyses}

We conducted all statistical analyses in $\mathrm{R}$ version 3.5.1 ( $\mathrm{R}$ Core Team, 2019). To investigate if the timing of singing was different between urban and rural great tit males, we compared the start, end and duration of the dawn chorus, last song of the day and total singing time. We performed an Exact Permutation test for dependent samples stratified by site in the $\mathrm{R}$ Coin package (Hothorn et al., 2008). We also conducted an Exact Permutation test for dependent samples stratified by site to compare the amount of singing between urban and rural males comparing number of songs sang during the dawn chorus, during the rest of the day and during each hour of the day. Furthermore to assess potential differences between rural and urban relative noise levels of low- and high-frequency bands for each hour of the day, we performed another Exact Permutation test stratified by site. The Exact Permutation tests allow deviation from a normal distribution, which was often the case for our variables (except for start relative to sunrise, number of songs during dawn chorus and some relative noise levels for certain hours). In order to analyze if the noise levels of the low- and high-frequency bands had an impact on the amount of singing, we used a Spearman's rank correlation test or Pearson's correlation test when the data were normally distributed. We correlated the number of songs and the amplitude levels relative to the noise average of the day for each site and each frequency band.

\section{RESULTS}

\section{Timing of the Dawn Chorus}

We analyzed a total of $513 \mathrm{~h}$ of recordings from 22 male great tits in 11 urban-rural pairs of sites. Urban great tits started to sing significantly earlier in the morning than rural great tits (mean \pm SE; Urban: $66 \pm 6.04$, range: 39-97 min before sunrise; Rural: $45 \pm 4.63$, range: $19-78$ min before sunrise; $z=-2.56$, $p<0.001$, Exact Permutation test; Figure 3A and Table 1). The average difference of 22 min was reflecting a persistent earlier start in the city throughout the season, although the difference varied substantially between about the same starting time up to a 50 min difference (Figure 3C). The duration of the dawn chorus and the end of the dawn chorus relative to sunrise were not significantly different between urban and rural birds (mean \pm SE; Duration, Urban: $64 \pm 11.26$, range: $12-153 \mathrm{~min}$; Rural: $58 \pm 7.23$, range: $29-119 \mathrm{~min} ; z=-0.44, p=0.68$, Exact Permutation test; Figure 3B; End, Urban: $-1 \pm 10.60$, range: -60 to $65 \mathrm{~min}$; Rural: $17 \pm 6.93$, range: -9 to $77 \mathrm{~min} ; z=1.11, p=0.30$, Exact Permutation test; Table 1). Note that differences in dawn chorus start were more consistent than duration differences, the 


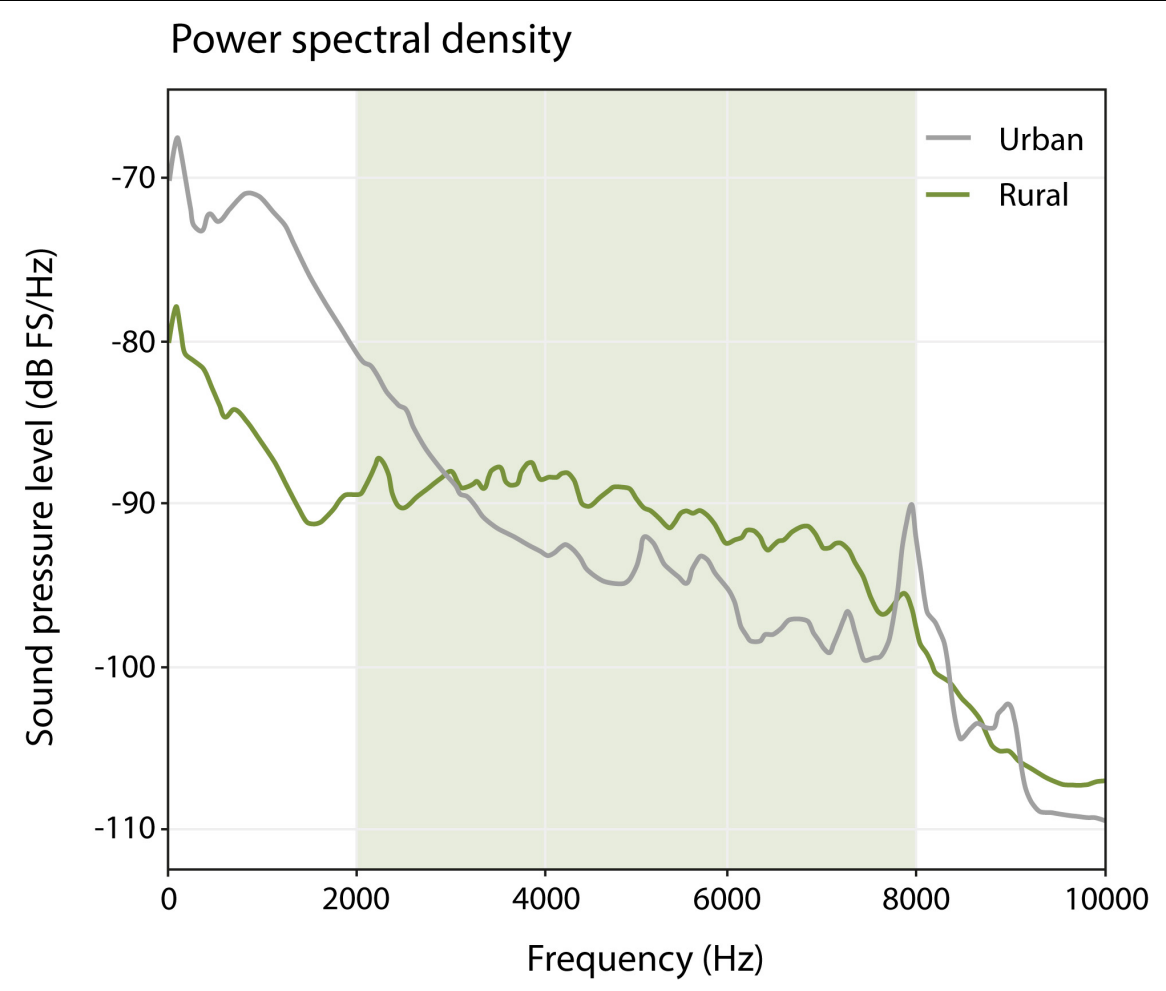

FIGURE 2 | Power spectral density plot (window length: 512, window type: Hann) of urban and rural sites, based on the average of 10 one-min samples for urban sites, and 10 one-min samples for rural sites, during the morning hour with most singing activity (5:30-6:30). The green-shaded area represents the frequency range used by great tits between 2000 and $8000 \mathrm{~Hz}$. Note that below $3000 \mathrm{~Hz}$, urban great tits have relatively more competition for acoustic space than rural birds, and above $3000 \mathrm{~Hz}$, rural birds have a relatively more noisy background.

latter of which were also more variable, for example ranging from $20 \mathrm{~min}$ until $160 \mathrm{~min}$ for urban birds (Figure 3B). The time of the last song of the day relative to sunset and the total time singing during the $24 \mathrm{~h}$ were also not significantly different between urban and rural great tits (mean \pm SE; Last song: Urban: $140 \pm$ 95.02, range: $8-979$ min; Rural: $38 \pm 11.27$, range: -2 to $118 \mathrm{~min} ; z=-1.07, p=0.38$, Exact Permutation test; Total singing: Urban: $833 \pm 47.18$, range: $462-958 \mathrm{~min}$; Rural: $862 \pm 6.98$, range: $823-887 \mathrm{~min} ; z=0.66 ; p=0.51$, Exact Permutation test; Table 1). The earliest song recorded was at 4:50 and the latest song was at 20:55 (Table 1), while we did not hear any songs recorded during nighttime.

\section{Amount of Singing Activity Over the Day}

We found that the numbers of songs sung by urban and rural great tits during the dawn chorus were not significantly different (mean \pm SE; Urban: $274 \pm 48.83$, range: $25-526$ songs; Rural: $322 \pm 47.74$, range: $126-638$ songs; $z=0.55, p=0.61$, Exact Permutation test; Figure 4A). In contrast to that, urban great tits sang significantly less songs than rural great tits during the rest of the day (mean \pm SE; Urban: $567 \pm 84.77$, range: 127-988 songs; Rural: $1058 \pm 174.42$, range: 460-2258 songs; $z=2.13, p=0.03$, Exact Permutation test; Figure 4B). We found more songs sung by rural than by urban birds for more than half of the $17 \mathrm{~h}$ of the day. At the hours starting at
$4: 30,7: 30,9: 30,10: 30,12: 30$ to $15: 30$ and $17: 30$ to $18: 30$, we found either a significant difference or a non-significant trend ( $p<0.05$ and $p=0.06-0.08$, respectively; Exact Permutation test; Figure 4C).

\section{Noise Levels and Fluctuations Over the Day}

The average noise levels, determined by 22 sets of peak level assessments, using the sound level meter (short-term noise measurements), were significantly higher for territories in urban than for territories in rural sites (mean $\pm \mathrm{SE}, n=11$, Urban: $53.6 \pm 1.9 \mathrm{~dB}$; Rural: $45.9 \pm 1.3 \mathrm{~dB}$; Exact Permutation test; $z=-2.41 ; p=0.01)$. We also found significant differences or non-significant trends $(p<0.05$ and $p=0.06-0.08$, respectively; Exact Permutation test) for certain hours in the fluctuating patterns over the day between urban and rural sites for both, the low- and high-frequency bands (Figures 5A,B), through 1,440 one-min measurements on the Song Meter data (longterm noise measurements). From a more general perspective, the low-frequency band $(200-400 \mathrm{~Hz})$, reflecting traffic noise, exhibited relatively high levels (above the noise average of the day) between 5:30 and 22:30, while it was relatively quiet (below the noise average of the day) between 00:30 and 4:30 (see Figure 5B). Although this pattern was generally true for both urban and rural sites, rural sites were relatively less quiet 


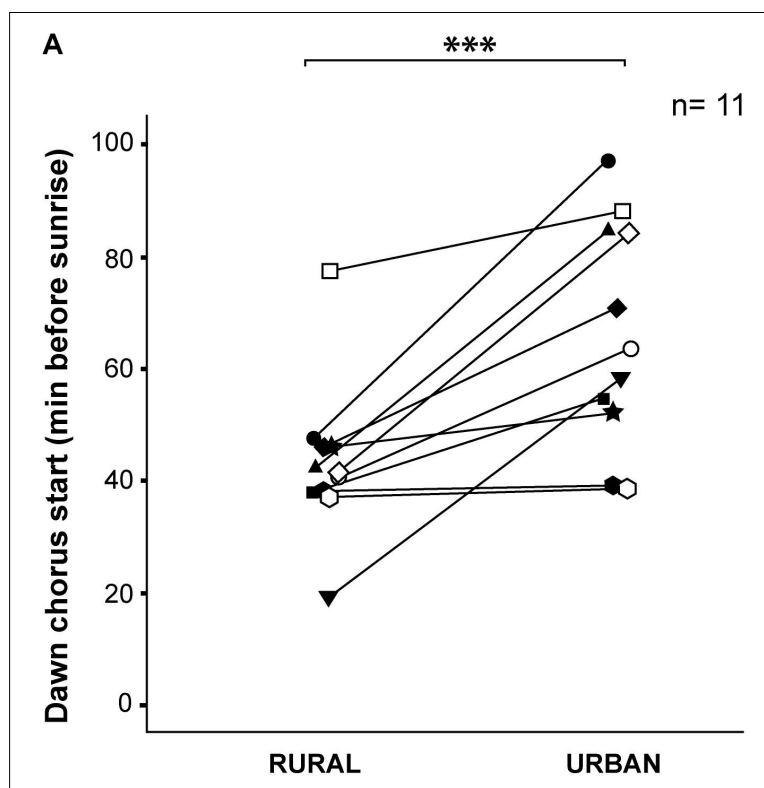

B

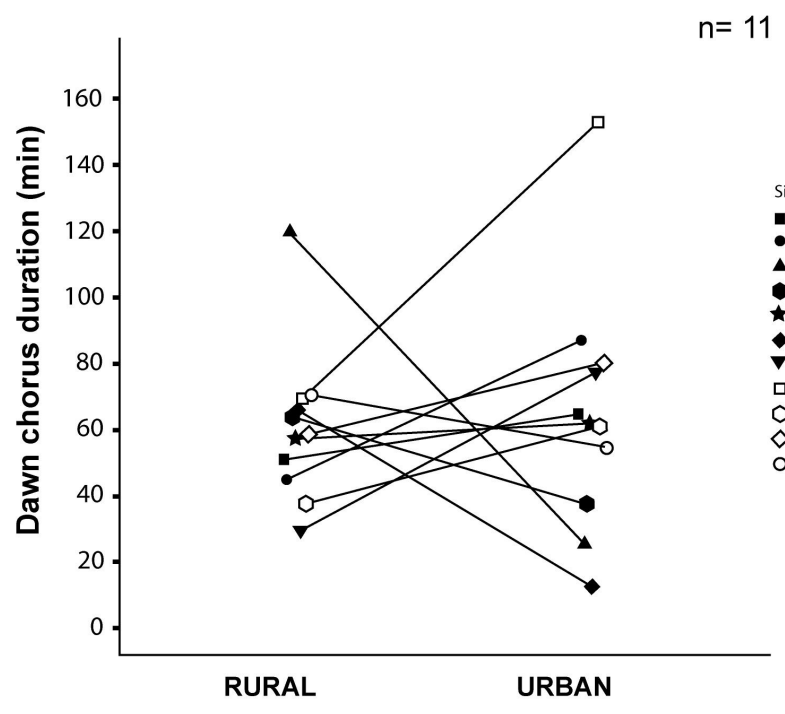

C

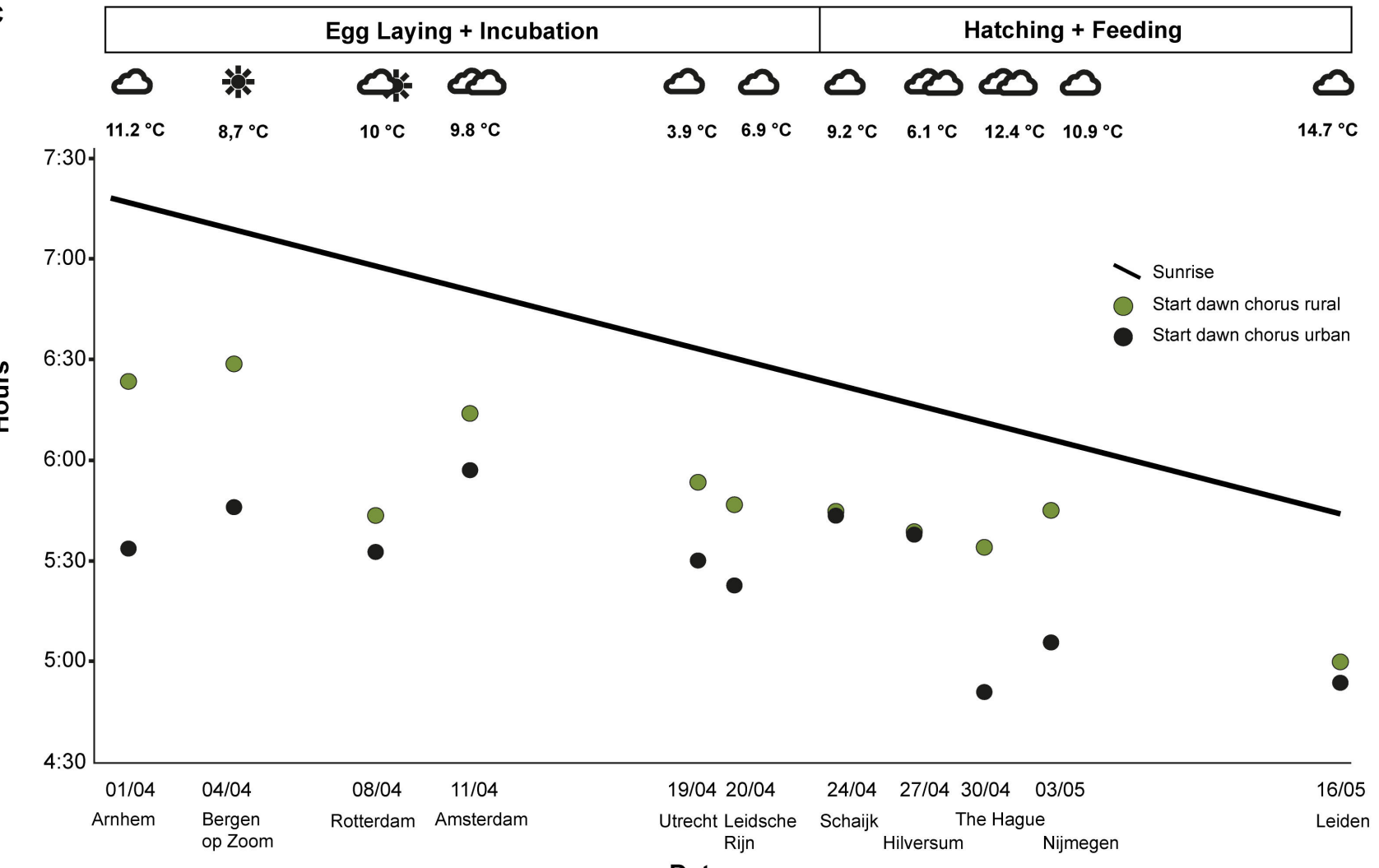

Date

FIGURE 3 | Timing of singing for urban and rural great tits: (A) Dawn chorus start time relative to sunrise (*** means a significant difference at $p<0.001$ level); (B) Duration of the dawn chorus (NS means not significant); and (C) Seasonal change of the start of the dawn chorus (line reflects changing sunrise). We indicated breeding phase and weather conditions for the sampling dates at the top and sampling date and pair location (by city name) at the bottom. See text for statistics.

during the night and early morning than urban sites (between 00:30 and 7:30), while urban sites were relatively more noisy in the late afternoon than rural sites (between 16:30 and 20:30).
The high-frequency band $(2000-4000 \mathrm{~Hz})$, reflecting general bird singing activity, was relatively high for both habitat types throughout the daytime (5:30-20:30), with highest levels as 


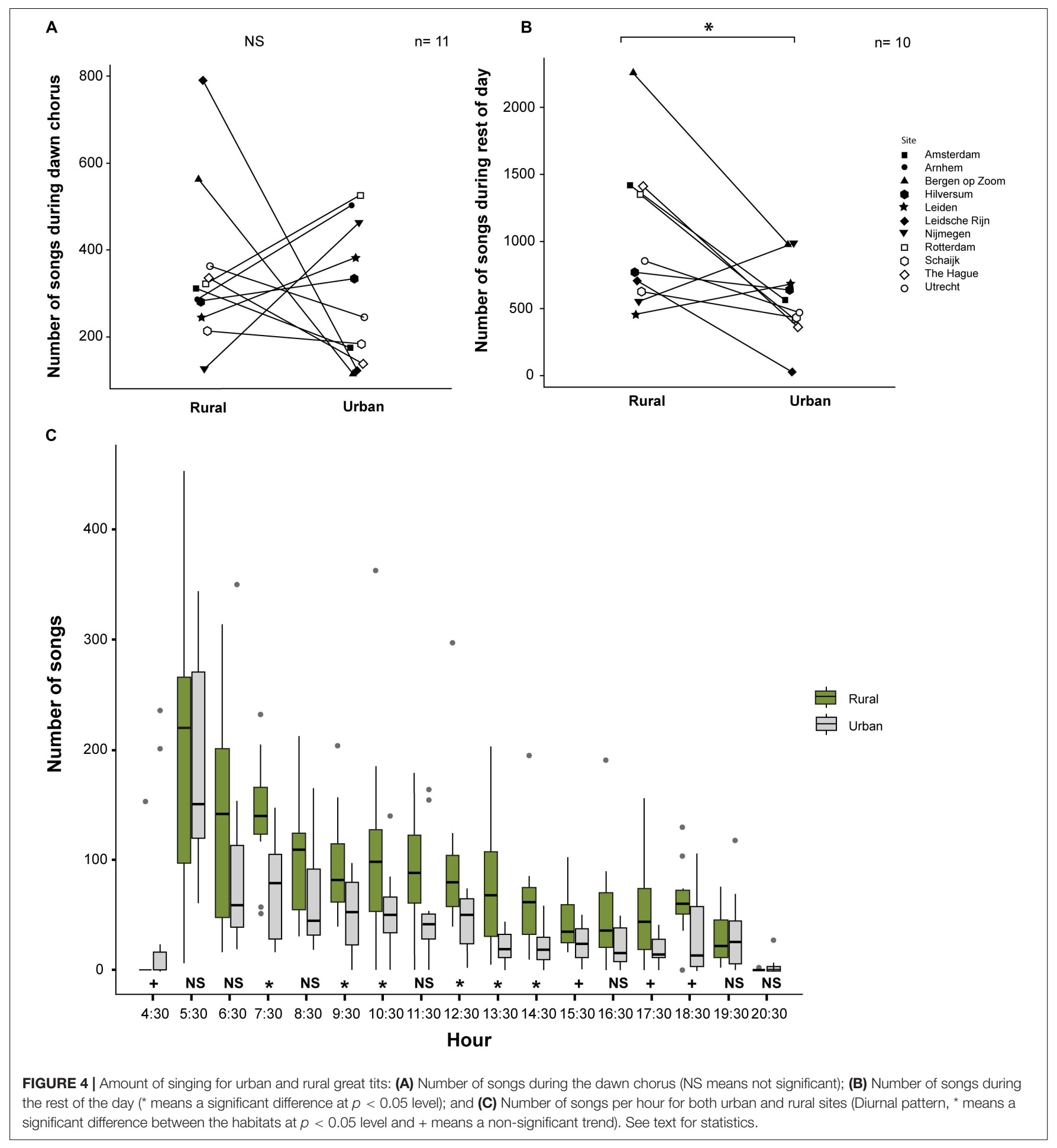

expected during the dawn (5:30-7:30) and dusk chorus (18:3020:30; Figure 5A).

\section{Covariation Between Noise Level and Singing Activity}

In addition to the previous description of the general noise patterns between rural and urban sites, we also analyzed the singing activity of the great tits in relation to the noise level fluctuations over the $24 \mathrm{~h}$ of a day. By starting to sing $22 \mathrm{~min}$ earlier, on average throughout the season, up to occasionally $50 \mathrm{~min}$ (around 5:30 or even earlier, late in the season), urban birds do shift singing activity into a relatively more quiet time period of the day. However, there were no significant differences in the amount of singing between birds in both habitats during 

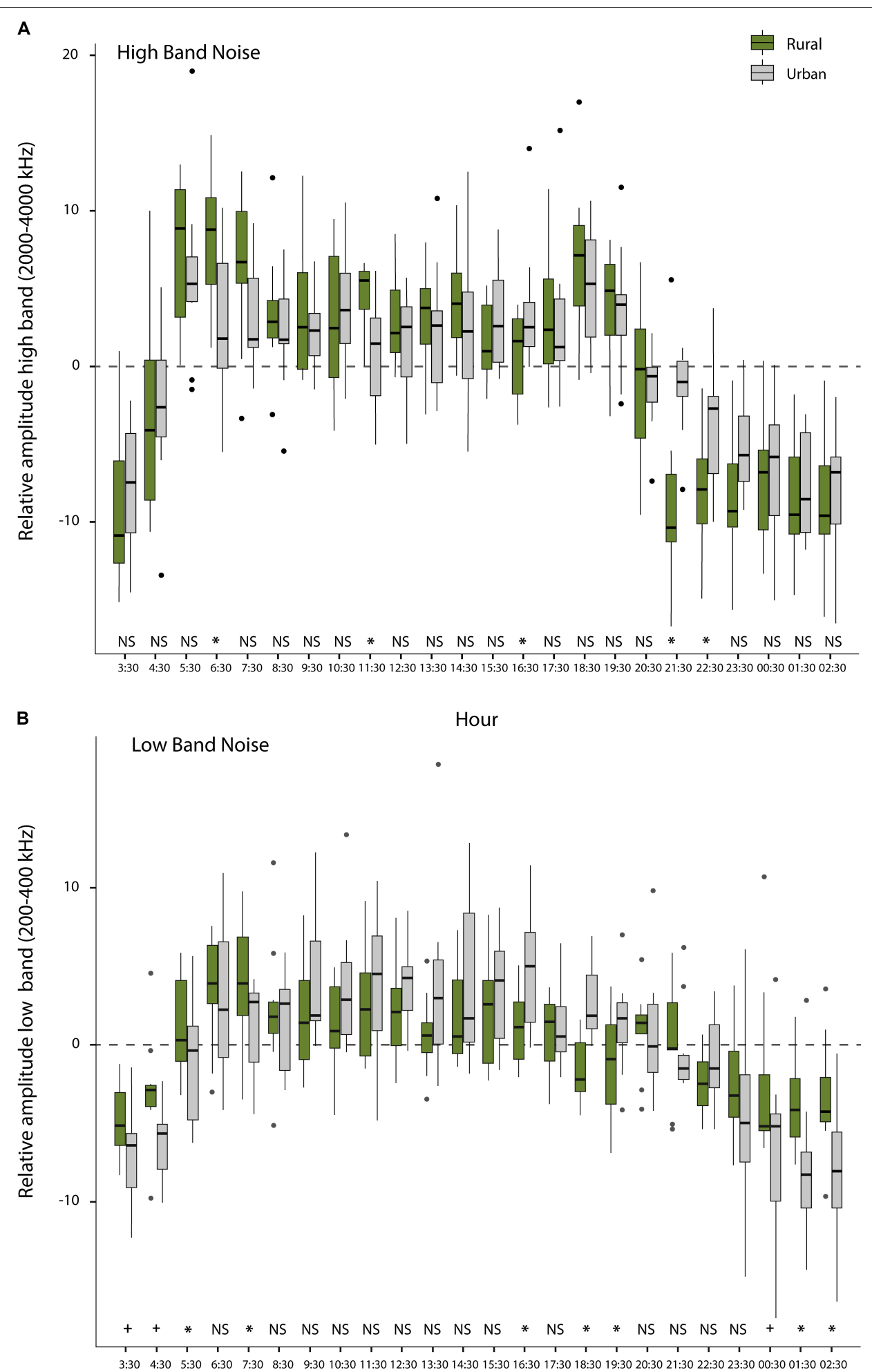

Hour

FIGURE 5 | Relative noise level fluctuations over the day: (A) Average noise level per hour subtracted from the overall mean of the day (represented with the zero value) for each habitat for the high-frequency band $(2000-4000 \mathrm{~Hz})$, reflecting fluctuations in local bird song activity other than that of the focal great tits; (B) Average noise level per hour subtracted from the overall mean of the day (represented with the zero value) for each habitat for the low-frequency band (200-400 Hz), reflecting local fluctuations caused by traffic noise ( ${ }^{*}$ indicates a significant difference at $p<0.05$ level and + means a non-significant trend). See text for statistics. The dashed line illustrates the overall noise of the day. 
those early hours (Figures 4C, 5B). Nevertheless, urban birds sang often less than rural birds later in the morning and in several afternoon time blocks, when urban noise levels were higher than at 5:30 (Figures 4C, 5B). We found an overall significantly positive correlation between the number of songs sung and the level of background noise of the low- and highfrequency bands, for both urban and rural sites (see results in Table 3 and Figures 6A-D). These correlations are driven and can be explained by the fact that: (1) during the $24 \mathrm{~h}$ analyzed, the quietest moments of the day, at night, are when birds are not singing; and (2) the loudest moments due to rush hours or overall high vocal activity by birds were also singing peaks for great tits. Removing the night hours from this analysis would remove many of the site-specific significant correlations: from 11 to 3 out of 20 for the low-frequency band and from 16 to 6 out of 20 for the high-frequency band (see Table 3).

\section{DISCUSSION}

We were able to show distinct differences in timing and amount of singing between urban and rural great tits in a well replicated and paired set of passive audio recordings of $24 \mathrm{~h}$. We found the following answers to our questions: (1) Urban great tits indeed sang earlier than nearby rural great tits; (2) Urban great tits did not sing more or for longer in the dawn chorus, but sang significantly less than rural birds over the rest of the day; and (3) Starting 22 mins earlier on average, up to $50 \mathrm{~min}$, in urban relative to nearby rural territories on the same day, resulted in more songs in a less noisy time of the day for city birds. However, in general great tits do not seem to avoid singing during the most noisy times of the day, as song activity level was positively correlated to relative ambient noise levels in the low-frequency band of 200-400 Hz, which is a good monitor of traffic noise.

\section{Patterns and Processes}

We were able to confirm what has been found in many studies: urban birds start singing earlier than rural birds (Bergen and Abs, 1997; Swaddle et al., 2015; Da Silva and Kempenaers, 2017). This pattern is not only known from cities, but has also been reported repeatedly for airports (Gil et al., 2015; Dominoni et al., 2016; Sierro et al., 2017). Our study is the first with a proper replication at the level of the habitat, with sampling of 11 urbanrural territories across the Netherlands. We also recorded a full 24-h cycle, which allowed us to analyze whether early morning adjustments concern a shift or extension of their active period. We were therefore able to show that urban birds started earlier, but that this does not affected how much they sang in the same hour bins during the dawn chorus compared to rural birds. The dawn chorus duration of urban great tits was also not significantly

TABLE 3 | Correlations between number of songs and noise amplitude levels relative to the noise average of the day, for each site (urban and rural) and for each frequency band (low band noise: 200-400 Hz; high band noise: 2000-4000 Hz).

\begin{tabular}{|c|c|c|c|c|c|c|c|c|c|}
\hline \multirow{3}{*}{ Site } & \multirow{3}{*}{$\begin{array}{l}\text { Urban/ } \\
\text { Rural }\end{array}$} & \multicolumn{4}{|c|}{$24 \mathrm{~h}$, including night hours } & \multicolumn{4}{|c|}{ Excluding night hours } \\
\hline & & \multicolumn{2}{|c|}{ Low band noise } & \multicolumn{2}{|c|}{ High band noise } & \multicolumn{2}{|c|}{ Low band noise } & \multicolumn{2}{|c|}{ High band noise } \\
\hline & & $\mathbf{R}$ & $\mathbf{p}$ & $\mathbf{R}$ & $\mathbf{p}$ & $\mathbf{R}$ & $\mathbf{p}$ & $\mathbf{R}$ & $\mathbf{p}$ \\
\hline Bergen op Zoom & Urban & 0.76 & $<0.001$ & 0.67 & $<0.001$ & $0.063^{a}$ & 0.82 & $-0.19^{a}$ & 0.047 \\
\hline Bergen op Zoom & Rural & -0.14 & 0.51 & 0.86 & $<0.001$ & $-0.064^{a}$ & 0.82 & $0.54^{a}$ & 0.037 \\
\hline Rotterdam & Urban & -0.3 & 0.16 & 0.49 & 0.015 & -0.66 & 0.007 & 0.18 & 0.52 \\
\hline Rotterdam & Rural & -0.22 & 0.31 & 0.26 & 0.22 & 0.3 & 0.28 & 0.39 & 0.15 \\
\hline Amsterdam & Urban & 0.35 & $0.09+$ & 0.66 & $<0.001$ & $-0.27^{a}$ & 0.33 & $-0.09^{a}$ & 0.74 \\
\hline Amsterdam & Rural & 0.61 & 0.002 & 0.81 & $<0.001$ & $0.49^{a}$ & $0.06+$ & $0.89^{a}$ & $<0.001$ \\
\hline Utrecht & Urban & 0.36 & $0.08+$ & 0.6 & 0.002 & 0.48 & $0.08+$ & 0.71 & 0.005 \\
\hline Utrecht & Rural & 0.59 & 0.002 & 0.64 & $<0.001$ & 0.47 & 0.007 & -0.045 & 0.87 \\
\hline Leidsche Rijn & Urban & 0.37 & $0.08+$ & 0.25 & 0.24 & 0.29 & 0.27 & -0.58 & 0.83 \\
\hline Leidsche Rijn & Rural & 0.56 & 0.004 & 0.78 & $<0.001$ & 0.38 & 0.16 & 0.21 & 0.46 \\
\hline Schaijk & Urban & 0.73 & $<0.001$ & 0.81 & $<0.001$ & 0.13 & 0.64 & 0.47 & $0.07+$ \\
\hline Schaiijk & Rural & 0.81 & $<0.001$ & 0.5 & 0.031 & 0.73 & 0.001 & -0.09 & 0.73 \\
\hline Hilversum & Urban & 0.6 & 0.002 & 0.66 & $<0.001$ & -0.27 & 0.32 & -0.12 & 0.67 \\
\hline Hilversum & Rural & 0.25 & 0.24 & 0.83 & $<0.001$ & -0.17 & 0.54 & 0.68 & 0.005 \\
\hline The Hague & Urban & 0.4 & $0.054+$ & 0.23 & 0.28 & -0.36 & 0.17 & -0.5 & 0.05 \\
\hline The Hague & Rural & 0.43 & 0.036 & 0.73 & $<0.001$ & -0.4 & 0.14 & 0.23 & 0.41 \\
\hline Nijmegen & Urban & 0.47 & 0.019 & 0.52 & 0.009 & 0.18 & 0.49 & -0.19 & 0.47 \\
\hline Nijmegen & Rural & 0.69 & $<0.001$ & 0.69 & $<0.001$ & $0.09+$ & 0.75 & 0.46 & $0.08+$ \\
\hline Leiden & Urban & 0.55 & 0.005 & 0.35 & $0.091+$ & -0.12 & 0.64 & -0.29 & 0.26 \\
\hline Leiden & Rural & 0.27 & 0.2 & 0.68 & $<0.001$ & 0.08 & 0.76 & 0.46 & $0.06+$ \\
\hline
\end{tabular}

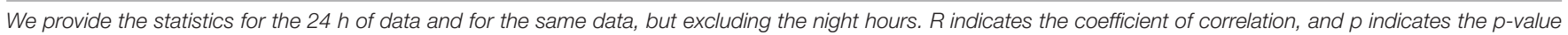

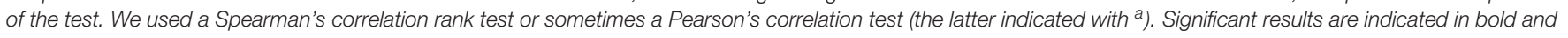
non-significant trend with a +. 


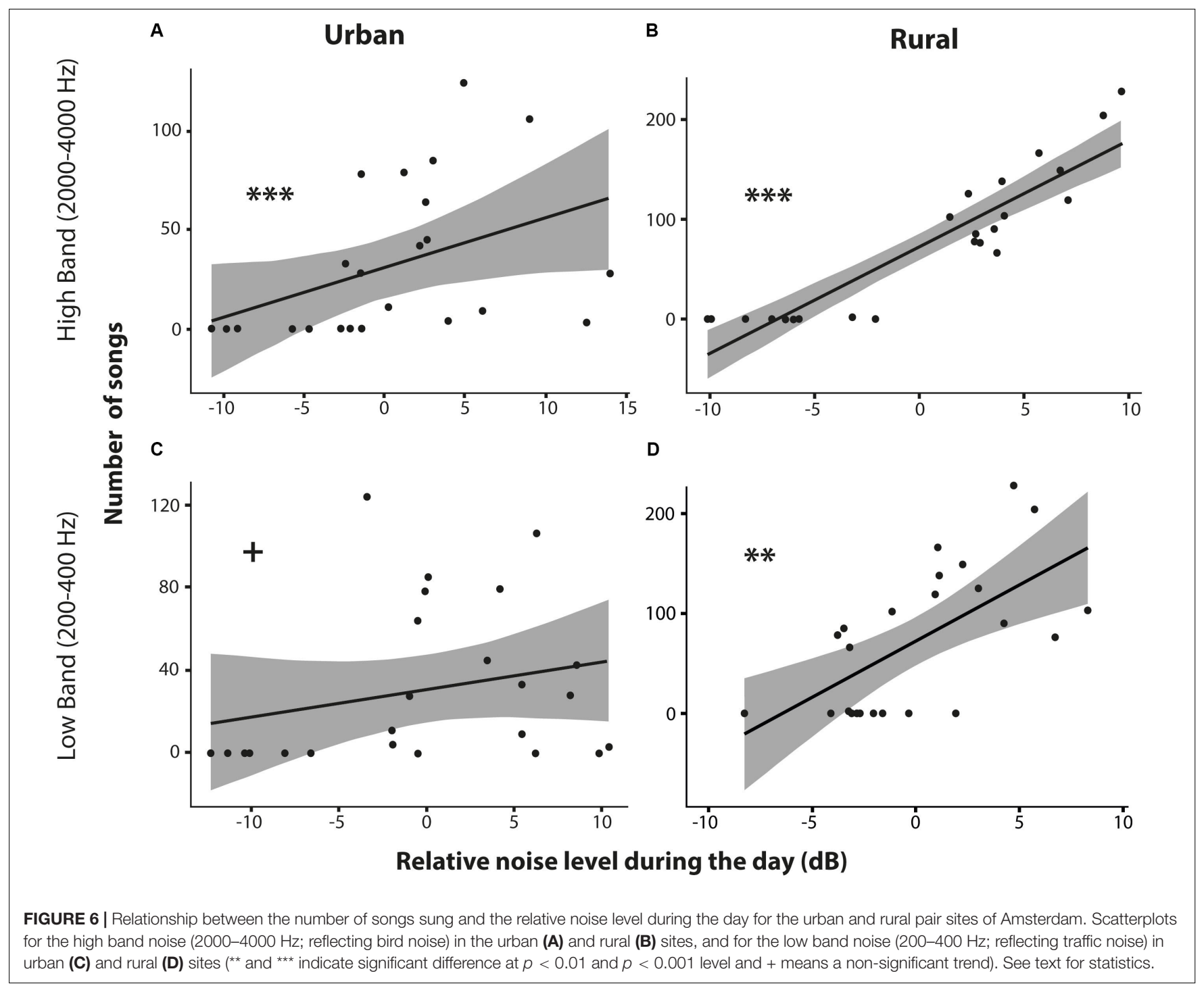

different from rural great tits, but we did find less song in city birds in several hour bins during the rest of the day. This pattern is, as far as we know, the first time this has been shown at this scale, but may indicate that rising early is associated with inserting periods of no or low activity more often during the rest of the day (c.f. de Jong et al., 2016; Raap et al., 2016).

Our data are in line with the growing awareness that the presence of human settlements and infrastructure can alter environmental cues and make urban and rural birds of the same species alter their activity patterns over the day. Cartwright et al. (2014) also conducted a study at high- and low-traffic sites in southern Ontario, Canada. They found that red-winged blackbirds (Agelaius phoeniceus), a semi-colonial breeder of marshlands, sang more at dawn and dusk at the rural sites and more during midday at the urban sites. They did not assess daily starting times or dawn chorus duration. It is, nevertheless, interesting that the patterns of singing effort divergence between urban and rural birds are quite different from ours on great tits. We found no difference in amount of singing at the dawn peak, while the divergence during the rest of the day, more singing in rural than urban, was opposite that of red-winged blackbirds. Not only were species and continent different between these studies, but the study of Cartwright et al. (2014) had another limitation that should be reason for caution. Although they recorded the three urban and two rural sites for relatively long periods ( 6 and 5 weeks, respectively), these periods were not overlapping (May till half-June for urban and end-June till end-July for rural), and a seasonal impact is therefore unknown and confounding with habitat (urban versus rural). As far as we know, there are no other studies that shed light on urban-rural patterns of 24-h activity cycles, but there are quite a few studies that explored the process.

Traffic noise and street lightening are two of the most prominent pollutants that are put forward as causing changes in avian rhythms (Nordt and Klenke, 2013; Lee et al., 2017). American robins (Turdus migratorius), for example, initiated their dawn chorus during the night, especially in areas with elevated artificial light levels (Miller, 2006). This pattern has been repeatedly confirmed afterward in several European species 
across latitude (Da Silva et al., 2014; Dominoni et al., 2014; Da Silva and Kempenaers, 2017). However, a study on European robins (Erithacus rubecula) reported nocturnal singing in urban territories with street lights, but attributed a larger proportion of the variation to daytime noise levels than to nighttime light levels (Fuller et al., 2007). For neither of these studies, it is clear whether there was a shift or an extension of activity, as data were not collected for the full day. Another recent study in urban greenspaces (Lee et al., 2017) also reported an impact of both light and noise on dawn chorus timing, with a larger role for artificial light at night, but with an opposite effect from the studies above. Traffic noise appears to be correlated to advancing dawn chorus in tropical bird species as well, where artificial light has apparently less of an effect, probably due to little variation in day length at their latitude (Dorado-Correa et al., 2016; Marín-Gómez and MacGregor-Fors, 2019). Independent of whether artificial light or traffic noise or a third factor is the underlying process, we would like to see more studies that describe the full-day patterns.

\section{Causes and Consequences}

A complete description of $24 \mathrm{~h}$ cycles is important for hypotheses about a mechanistic understanding of causal relationships in urban activity shifts and for the interpretation of potential consequences. However, experimental approaches will always be critical for proving causal relationships between the manipulated factors, such as light and/or noise level, and the behavioral read-out, for example, dawn chorus timing or singing effort (Arroyo-Solís et al., 2013; Yang and Slabbekoorn, 2014; Da Silva et al., 2017). However, confirmation that one factor plays a role, does not exclude an impact of another. Furthermore, potential consequences depend on many factors, as nighttime light and daytime noise levels may affect the timing and amount of singing, but directly or indirectly also other activities, such as foraging, nest building, scanning for predators, or seeking extra-pair interactions (Raap et al., 2017; Dominoni et al., 2020). We here just address adaptive and non-adaptive explanations for altered activity patterns in vocal behavior.

Adaptive explanations include positive consequences directly or indirectly related to the proven or hypothesized cause. Many studies have hypothesized that singing earlier in response to rising noise levels or at relatively noisy locations may yield a benefit in being more audible when singing at less noisy time periods of the day (Fuller et al., 2007). This was also partly true for great tits in the current study: the earlier dawn chorus yielded more songs in an earlier and quieter hour of the day, while overall urban birds sang less during the rest of the noisy day. However, we did not find a general negative correlation between singing effort and relative noise level. Cartwright et al. (2014) found a different urban-rural divergence pattern but argued similarly that singing less at dawn and dusk and more during the rest of the day was in line with avoiding the most noisy rush hours. Actual proof of any fitness consequences related to a noise-dependent shift does not exist yet, as far as we know.

Waking up by noisy human activities has also been suggested to be adaptive for those species that find food due to human activities (Arroyo-Solís et al., 2013). Two out of six songbird species responded by singing more early on nights of experimental exposure to local recordings of ambient noise in urban streets, which simulated an exceptionally early rise of people. The two species involved were the spotless starling (Sturnus unicolor) and the house sparrow (Passer domesticus), two typical commensals of human settlements that forage at feeding places. The earlier dawn singing due to artificially high light levels has been proposed to be beneficial for mating opportunities. In blue tits (Cyanistes caeruleus), for example, it has been shown that males close to street lights have higher reproductive success and are more attractive to females (Kempenaers et al., 2010), while early singers have been shown to be preferred by females in this species (Poesel et al., 2006). Such strong correlations have not been found for cases where birds sing earlier due to noisy territories, but may also apply, if not outweighed by other negative consequences.

Maladaptive explanations of altered vocal activity patterns are also diverse and may include detrimental consequences related to energy expenditure required for singing in earlier and colder times of day, singing more or with more effort to compensate for challenging signal-to-noise ratios, or singing at the expense of foraging for which there is ample evidence of a trade-off (Ydenberg, 1984; Cuthill and MacDonald, 1990; Grava et al., 2009). Singing earlier or singing less may also make birds more vulnerable to territorial intrusions and may force individuals into physical fight more often, which may bring risk of injury and increased chance of predation. This matches well with a pattern of noise-dependent aggression levels (Slabbekoorn, 2013), for which there is growing evidence from birds in cities (Phillips and Derryberry, 2018) and around airports (Wolfenden et al., 2019). Lower song activity during noisy daytime conditions, as found in our study, also matches with noise-induced rise in vigilance and distraction, which has been shown to reduce foraging efficiency (Quinn et al., 2006; Campbell et al., 2019). Again, actual proof of any negative fitness consequences does also not exist yet. It may also well be that vocal activity shifts in time or effort are not having any adaptive or maladaptive consequences.

\section{CONCLUSION}

We have shown conclusively that great tits in urban and rural areas differ in the timing of their singing activity: the dawn chorus starts earlier in the city and after that there is less singing activity in urban streets than in rural woodland. This concerns a confirmation of the early rise in cities as reported for many bird species and attributed sometimes to traffic noise during daytime, to artificial light at night, or both. However, this is the first well-replicated study at habitat level and the first that also scored activity for full 24 -h cycles. The latter revealed that an earlier singing start does not mean that urban birds sing more or less, or shorter or longer, during the dawn chorus, but that there is significantly less singing activity afterward during the rest of the day in cities compared to woodland. We currently have no insight into whether this can be related to any mechanistic or functional link between morning and afternoon activities, but this can be an interesting avenue for further study. The pattern 
shifts also appear to be moderate and may just be a case of nonrelevant plasticity, but evidence for or against positive or negative fitness consequences are largely lacking. Nevertheless, we have confirmed here that avian vocal activity shifts are a clear case of how anthropogenic effects on the natural environment influence fundamental aspects of daily life in the animal communities with which we share the urban habitat.

\section{DATA AVAILABILITY STATEMENT}

The raw data supporting the conclusions of this article will be made available by the authors, without undue reservation, to any qualified researcher.

\section{ETHICS STATEMENT}

Ethical review and approval was not required for this animal study in accordance with the local legislation and institutional requirements.

\section{AUTHOR CONTRIBUTIONS}

EB-C and HS designed the project as a part of EB-C's postdoctoral research stay at Leiden University. The fieldwork was

\section{REFERENCES}

Aide, T. M., Corrada-Bravo, C., Campos-Cerqueira, M., Milan, C., Vega, G., and Alvarez, R. (2013). Real-time bioacoustics monitoring and automated species identification. PeerJ 1:e103. doi: 10.7717/peerj.103

Arroyo-Solís, A., Castillo, J. M., Figueroa, E., Lopez-Sanchez, J. L., and Slabbekoorn, H. (2013). Experimental evidence for an impact of anthropogenic noise on dawn chorus timing in urban birds. J. Avian. Biol. 44, 288-296. doi: 10.1111/j.1600-048X.2012.05796.x

Ball, G. F. (1999). "Neuroendocrine basis of seasonal changes in vocal behavior among songbirds," in The Design of Animal Communication, eds M. Hauser and M. Konishi (Cambridge, MA: MIT Press), 213-253.

Barrueto, M., Ford, A. T., and Clevenger, A. P. (2014). Anthropogenic effects on activity patterns of wildlife at crossing structures. Ecosphere 5:27. doi: 10.1890/ ES13-00382.1

Berg, K. S., Brumfield, R. T., and Apanius, V. (2006). Phylogenetic and ecological determinants of the neotropical dawn chorus. Proc. R. Soc. B Biol. Sci. 273, 999-1005. doi: 10.1098/rspb.2005.3410

Bergen, F., and Abs, M. (1997). Etho-ecological study of the singing activity of the blue tit (Parus caeruleus), great tit (Parus major) and chaffinch (Fringilla coelebs). J. Ornithol. 138, 451-467. doi: 10.1007/BF01651380

Bergman, G. (1982). Die Veränderung der Gesangmelodie der Kohlmeise Parus major in Finnland und Schweden. Ornis Fenn. 57, 97-111.

Blake, J. G. (1992). Temporal variation in point counts of birds in a lowland wet forest in Costa Rica. Condor 94, 265-275. doi: 10.2307/1368816

Brown, T. J., and Handford, P. (2003). Why birds sing at dawn: the role of consistent song transmission. Ibis 145, 120-129. doi: 10.1046/j.1474-919X.2003. 00130.x

Bruni, A., Mennill, D. J., and Foote, J. R. (2014). Dawn chorus start time variation in a temperate bird community: relationships with seasonality, weather, and ambient light. J. Ornithol. 155, 877-890. doi: 10.1007/s10336-014-1071-7

Campbell, K. A., Proppe, D. S., Congdon, J. V., Scully, E. N., Miscler, S. K., and Sturdy, C. B. (2019). The effect of anthropogenic noise on feeding behaviour in black-capped chickadees (Poecile atricapillus). Behav. Process. 158, 53-58. doi: 10.1016/j.beproc.2018.10.015 carried out by EB-C, ZD, and LV. ZD and LV conducted part of the data processing. $\mathrm{CK}$ helped $\mathrm{EB}-\mathrm{C}$ with the rest of the data processing and data analysis. EB-C contributed to the writing of the manuscript together with HS. All authors contributed to the article and approved the submitted version.

\section{FUNDING}

This project was supported by a Mexican post-doctoral grant from CONACYT to EB-C. Funding for travel, stay, equipment, and processing came from the Institute of Biology Leiden, Leiden University, Netherlands.

\section{ACKNOWLEDGMENTS}

The authors would like to thank all the people who helped to localize appropriate great tit territories with actively singing males close to nest boxes in both noisy urban areas and more quiet rural areas. The authors also would like to thank those people who allowed access to their gardens, recreational parks, or natural protected areas, or supported them in other ways with the field work. The authors are especially grateful to the Dutch program "Vroege Vogels" that allowed them to advertise their study on national radio, which helped them reaching those people who were important to get sampling locations across the country.

Caorsi, V., Sprau, P., Zollinger, S. A., and Brumm, H. (2019). Nocturnal resting behaviour in urban great tits and its relation to anthropogenic disturbance and microclimate. Behav. Ecol. Sociob. 73:19. doi: 10.1007/s00265-018-2624-1

Cartwright, L. A., Taylor, D. R., Wilson, D. R., and Chow-Fraser, P. (2014). Urban noise affects song structure and daily patterns of song production in red-winged blackbirds (Agelaius phoeniceus). Urban Ecosyst. 17, 561-572. doi: 10.1007/ s11252-013-0318-z

Cuthill, I. C., and MacDonald, W. A. (1990). Experimental manipulation of the dawn and dusk chorus in the blackbird (Turdus merula). Behav. Ecol. Sociobio. 26, 209-216. doi: 10.1007/BF00172088

Da Silva, A., de Jong, M., van Grunsven, R. H. A., Visser, M. E., Kempenaers, B., and Spoelstra, K. (2017). Experimental illumination of a forest: no effects of lights of different colours on the onset of the dawn chorus in songbirds. R. Soc. Open Sci. 4:160638. doi: 10.1098/rsos.160638

Da Silva, A., and Kempenaers, B. (2017). Singing from North to South: latitudinal variation in timing of dawn singing under natural and artificial light conditions. J. Anim. Ecol. 86, 1286-1297. doi: 10.1111/1365-2656.12739

Da Silva, A., Samplonius, J. M., Schlicht, E., Valcu, M., and Kempenaers, B. (2014). Artificial night lighting rather than traffic noise affects the daily timing of dawn and dusk singing in common European songbirds. Behav. Ecol. 25, 1037-1047. doi: 10.1093/beheco/aru103

Da Silva, A., Valcu, M., and Kempenaers, B. (2015). Light pollution alters the phenology of dawn and dusk singing in common European songbirds. Philos. Trans. R. Soc. Lond. B Biol. Sci. 370, 20140126. doi: 10.1098/rstb.2014.0126

de Jong, M., Jeninga, L., Ouyang, J. Q., van Oers, K., Spoelstra, K., and Visser, M. E. (2016). Dose-dependent responses of avian daily rhythms to artificial light at night. Physiol. Behav. 155, 172-179. doi: 10.1016/j.physbeh.2015.12.012

Dominoni, D., Smit, J. A. H., Visser, M. E., and Halfwerk, W. (2020). Multisensory pollution: artificial light at night and anthropogenic noise have interactive effects on activity patterns of great tits (Parus major). Environ. Pollut. 256:113314. doi: 10.1016/j.envpol.2019. 113314

Dominoni, D. M., Carmona-Wagner, E. O., Hofmann, M., Kranstauber, B., and Partecke, J. (2014). Individual-based measurements of light intensity provide new insights into the effects of artificial light at night on daily rhythms of 
urban-dwelling songbirds. J. Anim. Ecol. 83, 681-692. doi: 10.1111/1365-2656. 12150

Dominoni, D. M., Greif, S., Nemeth, E., and Brumm, H. (2016). Airport noise predicts song timing of European birds. Ecol. Evol. 6, 6151-6159. doi: 10.1002/ ece3.2357

Dominoni, D. M., Helm, B., Lehmann, M., Dowse, H. B., and Partecke, J. (2013). Clocks for the city: circadian differences between forest and city songbirds. Proc. Biol. Sci. 280:20130593. doi: 10.1098/rspb.2013.0593

Dorado-Correa, A., Rodriguez-Rocha, M., and Brumm, H. (2016). Anthropogenic noise, but not artificial light levels predicts song behaviour in an equatorial bird. R. Soc. Open Sci. 3:160231. doi: 10.1098/rsos.160231

Frey, S., Fisher, J. T., Burton, A. C., and Volpe, J. P. (2017). Investigating animal activity patterns and temporal niche partitioning using camera-trap data: challenges and opportunities. Remote Sens. Ecol. Conserv. 3, 123-132. doi: 10. $1002 /$ rse2.60

Fuller, R. A., Warren, P. H., and Gaston, K. J. (2007). Daytime noise predicts nocturnal singing in urban robins. Biol. Lett. 3, 368-370. doi: 10.1098/rsbl.2007. 0134

Garson, P. J., and Hunter, M. L. (1979). Effects of temperature and time of year on the singing behaviour of wrens (Troglodytes troglodytes) and great tits (Parus major). Ibis 121, 481-487. doi: 10.1111/j.1474-919X.1979.tb0 6688.x

Gaynor, K. M., Hojnowski, C. E., Carter, N. H., and Brashares, J. S. (2018). The influence of human disturbance on wildlife nocturnality. Science 360, 1232-1235. doi: 10.1126/science.aar7121

Gil, D., Honarmand, M., Pascual, J., Perez-Mena, E., and Macias Garcia, C. (2015). Birds living near airports advance their dawn chorus and reduce overlap with aircraft noise. Behav. Ecol. 26, 435-443. doi: 10.1093/beheco/aru207

Grava, T., Grava, A., and Otter, K. A. (2009). Supplemental feeding and dawn singing in black-capped chickadees. Condor 111, 560-564. doi: 10.1525/cond. 2009.080061

Halfwerk, W., Bot, S., Buikx, J., Van Der Velde, M., Komdeur, J., Ten Cate, C., et al. (2011). Low songs lose potency in urban noise conditions. Proc. Natl. Acad. Sci. U.S.A. 108, 14549-14554. doi: 10.1073/pnas.1109091108

Halfwerk, W., Bot, S., and Slabbekoorn, H. (2012). Male great tit song perch selection in response to noise-dependent female feedback. Funct. Ecol. 26, 1339-1347. doi: 10.1111/j.1365-2435.2012.02018.x

Hart, P. J., Hall, R., Ray, W., Beck, A., and Zook, J. (2015). Cicadas impact bird communication in a noisy tropical rainforest. Behav. Ecol. 26, 839-842. doi: 10.1093/beheco/arv018

Hothorn, T., Bretz, F., and Westfall, P. (2008). Simultaneous inference in general parametric models. Biomed. J. 50, 346-363. doi: 10.1002/bimj.200810425

Hunter, M. L., and Krebs, J. R. (1979). Geographical variation in the song of the great tit (Parus major) in relation to ecological factors. J. Anim. Ecol. 48, 759-785. doi: 10.2307/4194

Kacelnik, A., and Krebs, J. R. (1983). The dawn chorus in the great tit (Parus major): proximate and ultimate causes. Behaviour 83, 287-309. doi: 10.1163/ 156853983 X00200

Kempenaers, B., Borgström, P., Loës, P., Schlicht, E., and Valcu, M. (2010). Artificial night lighting affects dawn song, extra-pair siring success, and lay date in songbirds. Curr. Biol. 20, 1735-1739. doi: 10.1016/j.cub.2010. 08.028

Krebs, J., Ashcroft, R., and Webber, M. (1978). Song repertoires and territory defence in great tit. Nature 271, 539-542. doi: 10.1016/S0003-3472(81)80029-2

Lee, J. G.-H., MacGrgor-Fors, I., and Yeh, P. J. (2017). Sunrise in the city: disentangling drivers of the avian dawn chorus onset in urban greenspaces. J. Avian Biol. 48, 955-964. doi: 10.1111/jav.01042

Lehtonen, L. (1983). The changing song patterns of the great tit Parus major. Ornis Fenn. 60, 16-21.

Lendrum, P. E., Crooks, K. R., and Wittemyer, G. (2017). Changes in circadian activity patterns of a wildlife community post high-intensity energy development. J. Mammal. 98, 1265-1271. doi: 10.1093/jmammal/ gyx097

Mace, R. (1987). The dawn chorus in the great tit (Parus major) is directly related to female fertility. Nature 330, 745-746. doi: 10.1038/330 $745 \mathrm{a} 0$

Marchand, P., Garel, M., Bourgoin, G., Dubray, D., Maillard, D., and Loison, A. (2014). Impacts of tourism and hunting on a large herbivore's spatio-temporal behavior in and around a French protected area. Biol. Conserv. 177, 1-11. doi: 10.1016/j.biocon.2014.05.022

Marín-Gómez, O. H., and MacGregor-Fors, I. (2019). How early do birds start chirping? Dawn chorus onset and peak times in a neotropical city. Ardeola 66, 327-341. doi: 10.13157/arla.66.2.2019.ra5

Martin, J., Basille, M., Van Moorter, B., Kindberg, J., Allaine, D., and Swenson, J. E. (2010). Coping with human disturbance: spatial and temporal tactics of the brown bear (Ursus arctos). Can. J. Zool. 88, 875-883. doi: 10.1139/Z10-053

Miller, M. W. (2006). Apparent effects of light pollution on singing behavior in American robins. Condor 108, 130-139. doi: 10.1093/condor/108.1.130

Mockford, E. J., and Marshall, R. C. (2009). Effects of urban noise on song and response behaviour in great tits. Proc. R. Soc. B 276, 2979-2985. doi: 10.1098/ rspb.2009.0586

Naguib, M., Diehl, J., Van Oers, K., and Snijders, L. (2019). Repeatability of signalling traits in the avian dawn chorus. Front. Zool. 16:27. doi: 10.1186/ s12983-019-0328-7

Nemeth, E., and Brumm, H. (2010). Birds and anthropogenic noise: are urban songs adaptive? Am. Nat. 176, 465-475. doi: 10.1086/656275

Nordt, A., and Klenke, R. (2013). Sleepless in town - Drivers of the temporal shift in dawn song in urban European blackbirds. PLoS One 8:e71476. doi: 10.1371/journal.pone.0071476

Nottebohm, F. (1981). A brain for all seasons: cyclical anatomical changes in songcontrol nuclei of the canary brain. Science 214, 1368-1370. doi: 10.1126/science. 7313697

Ogurtsov, S., Zheltukhin, A. S., and Kotlov, I. (2018). Daily activity patterns of large and medium-sized mammals based on camera traps data in the Central Forest Nature Reserve, Valdai Upland, Russia. Nat. Conserv. Res. 3, 68-88. doi: $10.24189 /$ ncr.2018.031

Pérez-Granados, C., Osiejuk, T. S., and López-Iborra, G. M. (2018). Dawn chorus interpretation differs when using songs or calls: the Dupont's Lark Chersophilus duponti case. PeerJ 6:e5241. doi: 10.7717/peerj.5241

Phillips, J. N., and Derryberry, E. P. (2018). Urban sparrows respond to a sexually selected trait with increased aggression in noise. Sci. Rep. 8:7505. doi: 10.1038/ s41598-018-25834-6

Poesel, A., Kunc, H. P., Foerster, K., Johnsen, A., and Kempenaers, B. (2006). Early birds are sexy: male age, dawn song and extrapair paternity in blue tits, Cyanistes (formerly Parus) caeruleus. Anim. Behav. 72, 531-538. doi: 10.1016/j.anbehav. 2005.10.022

Pohl, N. U., Slabbekoorn, H., Klump, G. M., and Langemann, U. (2009). Effects of signal features and environmental noise on signal detection in the great tit, Parus major. Anim. Behav. 78, 1293-1300. doi: 10.1016/j.anbehav.2009. 09.005

Quinn, J. L., Whittingham, M. J., Butler, S. J., and Cresswell, W. (2006). Noise, predation risk compensation and vigilance in the chaffinch Fringilla coelebs. J. Avian Biol. 37, 601-608. doi: 10.1111/j.2006.0908-8857.03781.x

R Core Team (2019). R: A Language and Environment for Statistical Computing. Vienna: R Core Team.

Raap, T., Pinxten, R., Casasole, G., Dehnhard, N., and Eens, M. (2017). Ambient anthropogenic noise but not light is associated with the ecophysiology of free-living songbird nestlings. Sci. Rep. 7:2754. doi: 10.1038/s41598-01702940-5

Raap, T., Pinxten, R., and Eens, M. (2016). Artificial light at night disrupts sleep in female great tits (Parus major) during the nestling period, and is followed by a sleep rebound. Environ. Pollut. 215, 125-134. doi: 10.1016/j.envpol.2016.04.100

Senar, J. C., Garamszegi, L. Z., Tilgar, V., Biard, C., Moreno-Rueda, G., Salmón, P., et al. (2017). Urban great tits (Parus major) show higher distress calling and pecking rates than rural birds across Europe. Front. Ecol. Evol. 5:163. doi: $10.3389 /$ fevo. 2017.00163

Sierro, J., Schloesing, E., Pavon, I., and Gil, D. (2017). European blackbirds exposed to aircraft noise advance their chorus, modify their song and spend more time singing. Front. Ecol. Evol. 5:68. doi: 10.3389/fevo.2017.00068

Slabbekoorn, H. (2013). Songs of the city: noise-dependent spectral plasticity in the acoustic phenotype of urban birds. Anim. Behav. 85, 1089-1099. doi: 10.1016/j. anbehav.2013.01.021

Slabbekoorn, H., and den Boer-Visser, A. (2006). Cities change the songs of birds. Curr. Biol. 16, 2326-2331. doi: 10.1016/j.cub.2006.10.008

Slabbekoorn, H., and Peet, M. (2003). Birds sing at a higher pitch in urban noise. Nature 424:267. doi: 10.1038/424267a 
Slabbekoorn, H., and Ripmeester, E. A. P. (2008). Birdsong and anthropogenic noise: implications and applications for conservation. Mol. Ecol. 17, 72-83. doi: 10.1111/j.1365-294X.2007.03487.x

Slagsvold, T., Dale, S., and Saetre, G. P. (1994). Dawn singing in the great tit (Parus major): mate attraction, mate guarding or territorial defense. Behaviour 131, 115-138. doi: 10.1163/156853994X00244

Stanley, C. Q., Walter, M. H., Venkatraman, M. X., and Wilkinson, G. S. (2016). Insect noise avoidance in the dawn chorus of Neotropical birds. Anim. Behav. 112, 255-265. doi: 10.1016/j.anbehav.2015.12.003

Swaddle, J. P., Francis, C. D., Barber, J. R., Cooper, C. B., Kyba, C. C. M., Dominoni, D. M., et al. (2015). A framework to assess evolutionary responses to anthropogenic light and sound. Trends Ecol. Evol. 30, 550-560. doi: 10.1016/ j.tree.2015.06.009

Ulgezen, Z. N., Kapyla, T., Meerlo, P., Spoelstra, K., Visser, M. E., and Dominoni, D. M. (2019). Preference and costs of sleeping under light at night in forest and urban great tits. Proc. R. Soc. B 286, 20190872. doi: 10.1098/rspb.2019. 0872

Wolfenden, A. D., Slabbekoorn, H., Kluk, K., and de Kort, S. R. (2019). Aircraft sound exposure leads to song frequency decline and elevated aggression in wild chiffchaffs. J. Anim. Ecol. 88, 1720-1731. doi: 10.1111/1365-2656. 13059

Yang, X. J., and Slabbekoorn, H. (2014). Timing vocal behavior: lack of temporal overlap avoidance to fluctuating noise levels in singing Eurasian wrens. Behav. Process. 108, 131-137. doi: 10.1016/j.beproc.2014.10.002

Ydenberg, R. C. (1984). The conflict between feeding and territorial defence in the Great Tit. Behav. Ecol. Sociobiol. 15, 103-108. doi: 10.1007/BF00299376

Conflict of Interest: The authors declare that the research was conducted in the absence of any commercial or financial relationships that could be construed as a potential conflict of interest.

Copyright (C) 2020 Bermúdez-Cuamatzin, Delamore, Verbeek, Kremer and Slabbekoorn. This is an open-access article distributed under the terms of the Creative Commons Attribution License (CC BY). The use, distribution or reproduction in other forums is permitted, provided the original author(s) and the copyright owner(s) are credited and that the original publication in this journal is cited, in accordance with accepted academic practice. No use, distribution or reproduction is permitted which does not comply with these terms. 